\title{
ERGONOMIC EVALUATION OF WORKING POSITION USING THE REBA METHOD - CASE STUDY
}

doi: $\quad 10.2478 /$ czoto-2019-0008

Date of submission of the article to the Editor: $30 / 11 / 2018$

Date of acceptance of the article by the Editor: 17/01/2019

Michał Pałęga ${ }^{1}$ - orcid id: 0000-0002-2779-431X

Dariusz Rydz ${ }^{1}$ - orcid id: 0000-0002-9985-8036

Dorota Wojtyto ${ }^{1}$ - orcid id: 0000-0003-2493-9808

Alexander Arbuz $^{2}$ - orcid id: 0000-0002-2081-0612

${ }^{1}$ Czestochowa University of Technology, Poland, palega.michal@wip.pcz.pl, rydz.dariusz@wip.pcz.pl,wojtyto.dorota@wip.pcz.pl,

${ }^{2}$ Karaganda State Industrial University, Republic of Kazakhstan

Abstract: Provision of professional work is very often associated with the worker's exposure to the occurrence of various types of threats. Some of the most important include those related to physical overload. Excessive strain on the musculoskeletal system can lead to muscle, ligament and tendon injuries. Therefore, it is necessary to evaluate the workplace in terms of its ergonomics. This paper presents the assessment of the load of the worker's movement system using the REBA method, which takes into account the location of: head with neck, torso, lower limb, as well as hands with the wrist, forearm and arm.

Keywords: REBA method, ergonomics, physical load, musculoskeletal system

\section{INTRODUCTION}

The performance of any work involves the worker's exposure to various types of hazards. The most popular ones are those causing excessive physical load, exceeding the endurance and functional efficiency of individual elements of the motor system. They can result from heavy and dynamic manual work, manual transport of objects (lifting), uncomfortable position at work and performing activities at high frequency and at high speed as well as static effort (Górska, 2007; Capodaglio, 2017). Excessive and prolonged loading of the musculoskeletal system is the cause of fatigue, and may also lead to injuries or diseases of muscles, ligaments, tendons, joints and other tissues. Disorders of the movement system most often affect such parts of the body as: the back (spine), neck, shoulders, upper limbs and lower limbs (Roman-Liu, 1996; Roman-Liu, 2009).

Most musculoskeletal disorders develop over time. Initially, health problems may be associated with microinjuries and moderate pain, however, with the passage of time may lead to more serious problems, and in chronic cases even lead to disability. 
Usually, there is no one factor affecting musculoskeletal disorders, but they depend on many factors that co-exist in the work environment. In addition to the physical factors of the work environment (nature and type of work, repetition of movements), individual factors (age, gender, lifestyle, health status) and organizational factors are also important (Kompier and Beek, 2008.; www.osha.europe.eu.pl; Podniece, 2008).

Overloading the movement system may lead not only to direct discomforts and injuries, but also to an increased number of faults, which may result in accidents at work. In addition, disorders of the musculoskeletal system also affect work efficiency. The article presents the chosen method on the example of two selected items taken during operations performed by the waterjet operator.

\section{METHOLOGY OF RESEARCH}

The REBA method is a fast method for assessing the functional and postural load of the whole body during work. This method allows to determine the risk associated with the occurrence of complaints and disorders of the musculoskeletal system, caused by the adopted body position during work, range of motion, strength, external load, muscle dynamics and type of grip and body position variability (Górska, 2007; Górska, 2010; Kong et al., 2018.). An unquestionable advantage of this method is simplicity of application and speed in obtaining reliable results. The final result determines the level of risk associated with the occurrence of the musculoskeletal system ailments and allows to indicate the directions of ergonomic actions reducing the level of this risk (Hignett and McAtamney, 2000; McAtamney and Hignett, 1995; Rizkya et al., 2018.). The analysis consists of 13 stages (steps) that have been divided into three main groups (Kathiravan and Gunarani, 2018).

Group A covers the first five stages $(1-5)$ and consists in determining the value of the load resulting from the position of the torso, neck, as well as the bending of the lower limbs and the method of support on the ground. The number of points should be determined in accordance with the items shown in Fig. $1-3$.

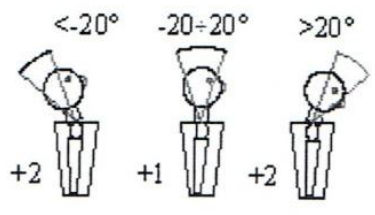

Source: (Blaszczok, 2018).

Fig. 1. Torso load

In addition, +1 if the torso is twisted or tilted sideways
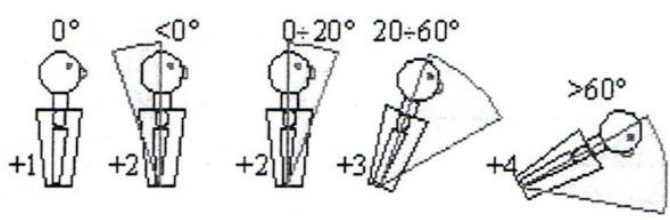

Fig. 2. Neck load

Source: (Blaszczok, 2018).

In addition, +1 if the neck is twisted or tilted sideways

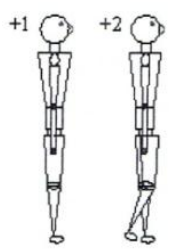

Fig. 3. Loading of lower limbs Source: (Blaszczok, 2018).

In addition, +1 if your knees are bent at an angle of $30^{\circ}-60^{\circ}$

In addition, +2 if the knees are bent at> $60^{\circ}$ (not applicable to the seat) 
Then, taking into account the individual values of the torso, neck and lower limbs position, the total value of the points should be estimated (value A), as shown in Tab.1.

Table 1

Total load indicator for the position of the torso, neck and lower limbs

\begin{tabular}{|c|c|c|c|c|c|c|c|c|c|c|c|c|c|}
\hline \multicolumn{14}{|c|}{ Indicator of total load on torso, neck and lower limbs positions } \\
\hline \multirow{2}{*}{\multicolumn{2}{|c|}{ Value A }} & \multicolumn{12}{|c|}{ Neck } \\
\hline & & \multicolumn{4}{|c|}{1} & \multicolumn{4}{|c|}{2} & \multicolumn{4}{|c|}{3} \\
\hline \multicolumn{2}{|c|}{ Legs } & 1 & 2 & 3 & 4 & 1 & 2 & 3 & 4 & 1 & 2 & 3 & 4 \\
\hline \multirow{5}{*}{ Torso } & 1 & 1 & 2 & 3 & 4 & 1 & 2 & 3 & 4 & 3 & 3 & 5 & 6 \\
\hline & 2 & 2 & 3 & 4 & 5 & 3 & 4 & 5 & 6 & 4 & 5 & 6 & 7 \\
\hline & 3 & 2 & 4 & 5 & 6 & 4 & 5 & 6 & 7 & 5 & 6 & 7 & 8 \\
\hline & 4 & 3 & 5 & 6 & 7 & 5 & 6 & 7 & 8 & 6 & 7 & 8 & 9 \\
\hline & 5 & 4 & 6 & 7 & 8 & 6 & 7 & 8 & 9 & 7 & 8 & 9 & 9 \\
\hline
\end{tabular}

Source: (Blaszczok, 2018).

The determined A value should be modified by points characterizing the load or external force acting on the employee, in accordance with the principle described in Tab. 2.

Table 2

Indicator of the load or external force affecting the employee

\begin{tabular}{|c|c|c|c|}
\hline \multicolumn{4}{|c|}{ Indicator of the load or external force affecting the employee } \\
\hline \multicolumn{4}{|c|}{ Load / Strength } \\
\hline 0 & 1 & 2 & +1 \\
\hline$<5 \mathrm{~kg}$. & $5-10 \mathrm{~kg}$. & $>10 \mathrm{~kg}$. & $\begin{array}{c}\text { Rapid, quick-gravity } \\
\text { loading }\end{array}$ \\
\hline
\end{tabular}

Source: (Blaszczok, 2018).

Group B contains the next five stages $(6-10)$, during which the load on upper limbs is analyzed. Positions of the arm, forearm and wrist are taken into account. During evaluation, the quality of the grip is also taken into account. The number of points should be determined in accordance with the items shown in Fig. 4 - 6.

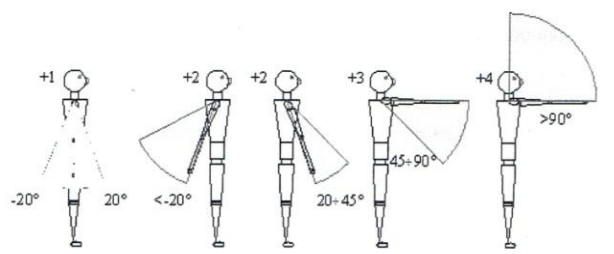

Fig. 4. Load of the arms

Source: (Blaszczok, 2018).

In addition, +1 if the arm is visited or twisted

In addition, +1 if the shoulder is raised

In addition -1 if the arm is lowered or supported 


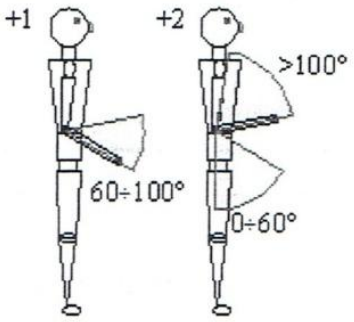

Fig. 5. Forearm load

Source: (Blaszczok, 2018).

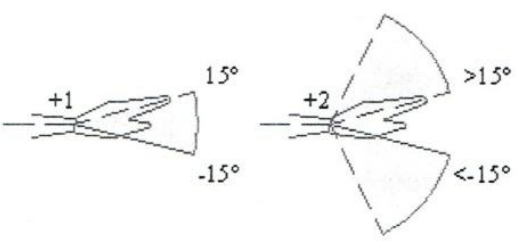

Fig. 6. Wrist load

Source: (Blaszczok, 2018).

In addition, +1 if your wrists are tilted or twisted

On the basis of the total value of points for arm, forearm and wrist positions, the assessment of the total load of arm, forearm and wrist positions (value B) should be determined in accordance with the guidelines described in Tab. 3

Table 3

Indicator of total load of arm, forearm and wrist positions

\begin{tabular}{|c|c|c|c|c|c|c|c|}
\hline \multicolumn{6}{|c|}{ Indicator for assessing the total load on arm, forearm and } \\
wrist positions \\
\hline \multirow{2}{*}{ Value B } & \multicolumn{6}{|c|}{ Forearm } \\
\cline { 2 - 9 } \multicolumn{2}{|c|}{} & \multicolumn{5}{|c|}{1} & \multicolumn{3}{c|}{2} \\
\hline \multirow{2}{*}{ Wrist } & 1 & 2 & 3 & 1 & 2 & 3 \\
\hline \multirow{4}{*}{ Arm } & 1 & 1 & 3 & 3 & 1 & 2 & 3 \\
\cline { 2 - 9 } & 2 & 1 & 2 & 3 & 2 & 3 & 4 \\
\cline { 2 - 9 } & 3 & 3 & 4 & 5 & 3 & 5 & 5 \\
\cline { 2 - 8 } & 4 & 4 & 5 & 5 & 5 & 6 & 7 \\
\cline { 2 - 8 } & 5 & 6 & 7 & 8 & 7 & 8 & 8 \\
\cline { 2 - 8 } & 6 & 7 & 8 & 8 & 8 & 9 & 9 \\
\hline
\end{tabular}

Source: (Blaszczok, 2018).

The value B should be modified taking into account the possibility of gripping, according to assumptions:

- well-fitting handles with an element enabling a comfortable grip (0);

- grip with hands, acceptable, but not ideal or comfortable, using other parts of the body $(+1)$;

- uncomfortable or impossible hand grip $(+2)$;

- no handles, no safety grip. It is not possible to hold even when using other parts of the body $(+3)$

Group $\mathbf{C}$ is the last three stages $(11-13)$, consisting in determining the final result, taking into account the type of effort (static effort, repetition, fast and large changes in body posture) and its interpretation. The value of $\mathrm{C}$ is determined on the basis of the final values of $A$ and $B$, as described in Tab. 4. The result obtained should be modified by the number of points characterizing the employee's activity:

- if at least one of the parts of the body remains static for longer than $1 \mathrm{~min}(+1)$; 
- if having a small range of activities occurs at least 4 times per minute (except walking) $(+1)$;

- if the action causes sudden, large changes in the body position or the activity is performed on an unstable basis $(+1)$.

Table 4

REBA indicator

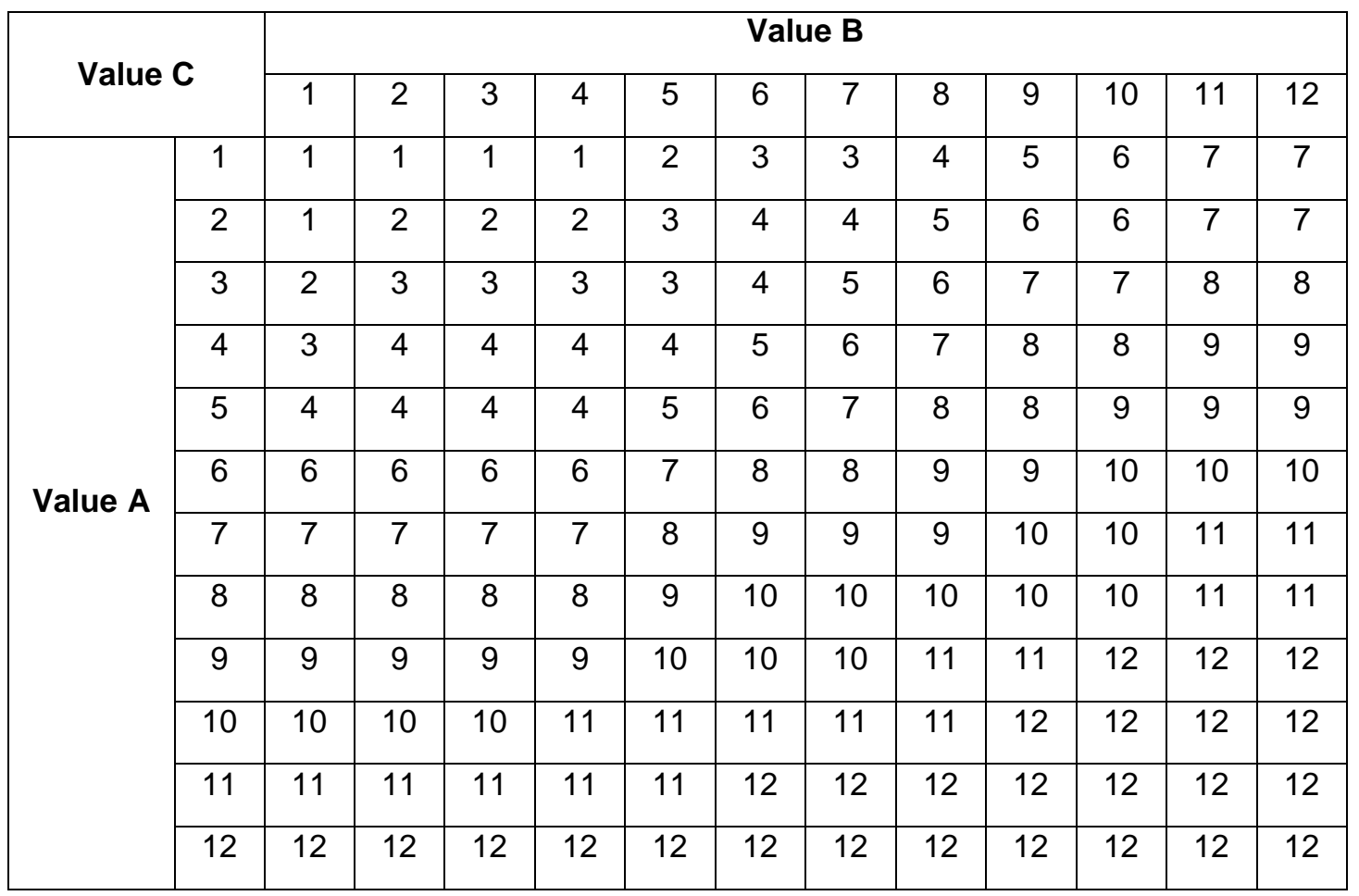

Source: (Blaszczok, 2018).

The comparison of obtained result of the total REBA with the values listed in Tab. 5 allows to assess the risk of developing complaints from the motor system. It also as assess the necessity of using ergonomic intervention, in order to reduce the level of risk.

Table 5

REBA rating

\begin{tabular}{|c|c|c|}
\hline Value C & Risk & Action \\
\hline 1 & Negligible & Acceptable position \\
\hline $2 \div 3$ & Small & Possible change requirement \\
\hline $4 \div 7$ & Medium & Need to conduct further research, change requirement \\
\hline $8 \div 10$ & Big & $\begin{array}{c}\text { The requirement of an immediate concept of detailed } \\
\text { research and changes }\end{array}$ \\
\hline$>11$ & Very big & Requirement of immediate changes \\
\hline
\end{tabular}

Source: (Górska, 2010).

\section{RESULTS}

The position of the waterjet operator was selected for the assessment. Waterjet cutting technology is a unique, modern technology that allows cutting out various, even the most complex shapes in a wide range of materials, from soft rubber and plastics to the hardest metals and ceramics. 
The operating environment of the waterjet cutting machine is characterized by the presence of many hazardous and harmful factors. Among them should be indicated: high pressure water jets, strong electromagnetic field, electric current, laser radiation, abrasive particles and sawdust filings. In addition, there is noise up to $95 \mathrm{~dB}$ within the station.

Due to the presence of harmful environmental factors, employees are required to comply with the basic principles of occupational health and safety, as well as the use of personal protective equipment. These include hearing protectors, eye protectors (up to $6 \mathrm{~m}$ around the machine), protective clothing, work shoes (with finger guard) and protective gloves. It is also forbidden to wear clothing or other loosely hanging items (eg jewelry). In addition, it is advisable to clean the area around the machine daily. Because accumulated particles from material cutting and abrasive can cause breathing difficulties and respiratory infections. In order to eliminate the risk of slipping, always wipe off spilled water or oil from the floor, and it is recommended to lay a special rubber mat in front of the machine with drain holes and grooves.

Working at a waterjet operator's station requires physical activity from the worker and taking various body positions. Materials for the station are transported with a forklift or a crane, after which on the working table, the cutters are inserted with a forklift or manually by the operator (in the case of objects with a weight of approx. $1 \mathrm{~kg}$ ). The pace of work at the post is not forced, and from the observation and interview carried out it follows that it does not cause an excessive physical load on the employee. Operators only complain about fatigue, but they do not report pain.

The employee performs the activities in accordance with the established process. The machine is controlled by a computer, cutting is done using a cutting plotter (cutting station).

Two body positions accepted by the waterjet operator were accepted for the assessment: A - when setting the "zero point" on the indicator (Fig. 7) and B - when adjusting the material (element) under the working head (Fig 8.).

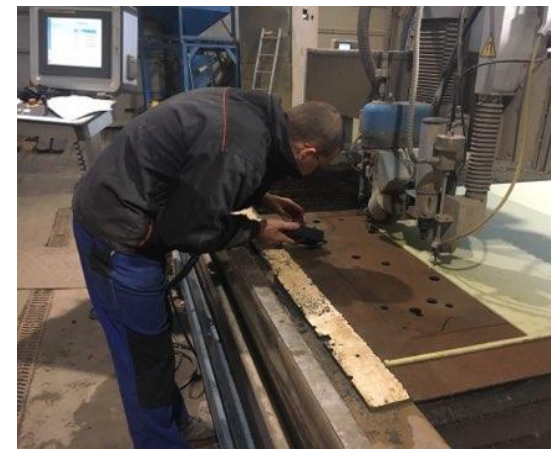

Fig. 7. Body A position when setting the "zero point" on the indicator

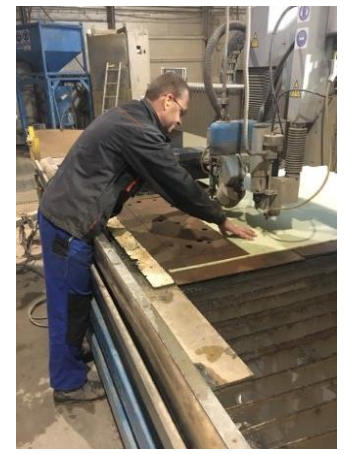

Fig. 8. Body position $B$ when adjusting the material (element) under the working head

In the position of the body marked as A, the worker keeps upright limbs. In turn, the back of the employee is significantly inclined forward, and the neck tilted back. The operator's arm is slightly tilted forward (in the range of $0-20^{\circ}$ ), while the angle between the arm and the forearm oscillates between $60-100^{\circ}$. The wrists are practically not tilted, and the right one is additionally twisted. An external load of up to $5 \mathrm{~kg}$ is applied to the employee. The quality of the grip is correct, the handles are matched, but not perfect. 
The muscles of some body segments remain in a static position for more than 1 minute, however, selected muscle groups perform dynamic work, repeatable at least 4 times per minute. The code values assigned to the body position $A$ are shown in tab. 6 , and the overall result of the REBA assessment in tab. 7.

The position of the body marked $B$ is also characterized by straightened lower limbs, and the operator's trunk is tilted forward at an angle above $30^{\circ}$. In addition, the employee also has delicate neck inclinations to the back. There are no additional forces or external loads acting on the employee during the activities. The operator's arm is raised and bent at an angle of $90^{\circ}$, while the angle between the arm and the forearm is about $0^{\circ}$. The wrist is raised dorsally above $15^{\circ}$. The muscles of selected parts of the body perform static work over 1 minute. According to the assumptions of the REBA method, the code values assigned to body positions $B$ are presented in tab. 6 , and the overall result of the REBA assessment (value C) tab. 7.

Table 6

Body position codes for position $A$ and position $B$

\begin{tabular}{|l|l|l|l|c|c|c|c|}
\hline \multicolumn{1}{|c|}{ Code } & $\begin{array}{c}\text { Position } \\
\text { A }\end{array}$ & $\begin{array}{c}\text { Position } \\
\text { B }\end{array}$ & \multicolumn{2}{c|}{ Code } & \multicolumn{2}{c|}{ Position A } & \multicolumn{2}{c|}{ Position B } \\
\hline $\begin{array}{l}\text { Neck } \\
\text { position code }\end{array}$ & 1 & 1 & Arm position code & $\mathrm{L}$ & $\mathrm{R}$ & $\mathrm{L}$ & $\mathrm{R}$ \\
\cline { 4 - 9 } & & 1 & 1 & 1 & 4 & 4 \\
\hline $\begin{array}{l}\text { Leg position } \\
\text { code }\end{array}$ & 1 & 3 & $\begin{array}{l}\text { Forearm position } \\
\text { code }\end{array}$ & 1 & 1 & 2 & 2 \\
\hline $\begin{array}{l}\text { torso } \\
\text { position code }\end{array}$ & 4 & wrist position code & $\begin{array}{c}1+1= \\
2\end{array}$ & $1+1$ & 2 & 2 \\
\hline External load & 0 & 0 & Handle & 0 & 0 & 0 & 0 \\
\hline Value A & $\mathbf{3}$ & $\mathbf{2}$ & Value B & $\mathbf{4}$ & $\mathbf{4}$ & $\mathbf{6}$ & $\mathbf{6}$ \\
\hline
\end{tabular}

Table 7

REBA value for body position $A$ and body position $B$

\begin{tabular}{|l|l|l|}
\hline \multicolumn{3}{|c|}{ Value C } \\
\hline & Position A & Position B \\
\hline Value A & 3 & 2 \\
\hline Value B & 4 & 6 \\
\hline Activity & $1+1=2$ & 1 \\
\hline Value C & $\mathbf{5}$ MEDIUM & $\mathbf{5}$ MEDIUM \\
\hline
\end{tabular}

The final mark for position A and item B is 5 , hence the risk is on the medium level, which is connected with undertaking further research in this respect and recommendation to introduce changes reducing the risk.

\section{CONCLUSION}

In accordance with applicable legal regulations (Labor Code), the employer is obliged to ensure safe and hygienic conditions at every workplace. In order to fulfill this obligation, it is necessary to recognize and assess the existing hazards, including those related to the burden of the musculoskeletal system. One of the methods designed and used by OSH services for this purpose is the REBA risk assessment method. It comprehensively covers the entire employee's musculoskeletal system, related to maintaining the forced position of the body, using force and the action of external load while performing specific activities at the workplace.

In this paper, two body positions were accepted by the waterjet operator when performing activities related to determining the "zero point" (position $A$ ) and adjusting 
the material (element) under the working head (position B). The analysis shows that the level of risk associated with the occurrence of musculoskeletal disorders is at an average level. This means that the company in question should undertake further research in the field of ergonomics of the workplace and measures to reduce the risk of occurring threats. Significant in this respect is the consideration of the employee's individual predispositions. Indeed, as the available literature on the subject indicates among the factors affecting the perception of musculoskeletal disorders, physical and psychophysical factors are included in addition to physical factors. Therefore, the final decisions related to the organization of a workplace in terms of its ergonomics should take into account all these elements. To sum up, it should be pointed out that the problem related to the reorganization of workplaces aimed at reducing the risk of discomfort of the motor system will be the subject of further research and deliberations in subsequent publications.

\section{REFERENCES}

Blaszczok, M., 2018. Ergonomia bezpiecznej i higienicznej pracy. PŚ, Gliwice.

Capodaglio, E.M., 2017. Occupational risk and prolonged standing work in apparel sales assistants. International Journal of Industrial Ergonomics, No. 60, 53-59.

Górska, E., 2007. Ergonomia. Oficyna Wydawnicza PW, Warszawa.

Górska, E., 2010. Metody oceny ryzyka zawodowego. Wydział Zarządzania Politechniki Warszawskiej, Warszawa.

Hignett, S., McAtamney, L., 2000. Rapid Entire Body Assessment (REBA): Applied Ergonomics 31, 201-205.

Kathiravan, S., Gunarani, G.I., 2018. Ergonomic performance assessment (EPA) using RULA and REBA for residential construction in Tamil Nadu. International Journal of Civil Engineering and Technology, 9(4), 836-843.

Kompier, M., A von der Beek, 2008. Psychosocial factors at work and musculoskeletal disorders: Scandinavian Journal of Work and Environmental Health, 323-325.

Kong, Y.-K., Lee, S.-Y., Lee, K.-S., Kim, D.-M., 2018. Comparisons of ergonomic evaluation tools (ALLA, RULA, REBA and OWAS) for farm work. International Journal of Occupational Safety and Ergonomics, 24(2), 218-223.

McAtamney, L., Hignett S., 1995. REBA: a rapid entire body assessment method for investigating work related musculoskeletal disorders, Proceeding of the Ergonomics Society of Australia, Adelaide. ESA, Adelaide, 45-51.

Podniece, Z., 2008. Work-related musculoskeletal disorders: prevention report. European Communities, Luxembourg.

Rizkya, I., Syaphputri, K., Sari, RM., Anizar, Siregar I., 2018. Evaluation of work posture and quantification of fatigue by Rapid Entire Body Assessment (REBA). IOP Conf. Series: Materials Science and Engineering 309.

Roman-Liu, D., 1996. Obciążenie układu mięśniowo-szkieletowego na stanowisku pracy. Bezpieczeństwo Pracy, Warszawa, 2-5.

Roman-Liu, D., 2009. Ocena rozwoju dolegliwości mięśniowo-szkieletowych z zastosowaniem metody REBA. Bezpieczeństwo Pracy, Warszawa, 12-15.

The Act of June 26, 1974 - Labor Code (Journal of Laws of 2016, item 1666). http://www.nexgenergo.com/ergonomics/ergointeluea.html

http://www.osha.europa.eu

Internal materials of the enterprise. 